\title{
Control and location of acyl-hydrolysing phospholipase activity in pathogenic mycobacteria
}

\author{
Paul R. Wheeler* and Colin Ratledge \\ Department of Applied Biology, University of Hull, Hull HU6 $7 R X, U K$
}

(Received 9 September 1991; revised 11 November 1991; accepted 19 November 1991)

\begin{abstract}
Phospholipase activities releasing fatty acyl moieties from phosphatidylcholine and phosphatidylethanolamine and lysophospholipase activity releasing fatty acid from lyso-phosphatidylcholine were detected in both Mycobacterium microti and Mycobacterium avium. Fatty acyl groups were released from both the 1- and 2-positions of phosphatidylcholine. Generally, phospholipase activities of $M$. avium were cryptic while phospholipase activities of $M$. microti were located on the bacterial surface. However, intact $M$. microti did not release fatty acids from phospholipids faster than $M$. avium. Neither Mycobacterium secreted acyl-hydrolysing phospholipase activity. All phospholipase activities were stimulated by including phospholipids in growth media: generally, cell extracts contained 6- to 15-fold higher specific activities than extracts from mycobacteria grown in media without added phospholipid. However, not all phospholipase activities were stimulated to the same degree in any given set of conditions, suggesting the existence of more than one phospholipase gene in each Mycobacterium.
\end{abstract}

\section{Introduction}

Phospholipases that hydrolyse lecithin (phosphatidylcholine) have been detected in Mycobacterium lepraemurium (Kashiwabara et al., 1980), M. bovis (Kondo et al., 1985), and $M$. leprae (Wheeler \& Ratledge, 1991). In the latter, activity was surprisingly high, around $25 \%$ of the specific activity found in $M$. microti that had been grown in a lecithin-rich medium, which might be expected to induce phospholipase activity (Wheeler \& Ratledge, 1991).

High activity of phospholipase may suggest a role for it in intracellular environments as pertain with $M$. leprae and other pathogenic mycobacteria. As the enzyme activity did not appear, in general, to be exposed to the environment of the leprosy bacilli, it was suggested that its role may be mainly in the provision of fatty acids for bacterial growth rather than movement of the cells into, or out of host cells (Wheeler \& Ratledge, 1991).

If phospholipids are substrates for intracellular mycobacteria, they must be present in host cells and should induce phospholipase activity in the mycobacteria as

- Author for correspondence. Present address: London School of Hygiene and Tropical Medicine, Keppel Street, London WC1E 7HT, UK. Tel. (071) 636 8636; fax (071) 6374314.

Abbreviation: ANDS, 7-diazonaphthalene-1,3-disulphonic acid. exogenous phospholipids are generally required to induce high microbial phospholipase activity (Finnerty, 1989). Thus the major objective of this study was to compare activities in mycobacteria that can be grown as intracellular parasites in experimental animals as well as in media free of phospholipids. The control of phospholipase activity was then investigated further by comparing activities in the same mycobacteria (using $M$. avium and $M$. microti) grown in defined media with and without phospholipids.

Using mycobacteria that can be grown axenically also allowed the investigation of whether they could secrete phospholipase into their environment and thus, after all, have the possibility of attacking and possibly damaging host cell membranes. These data are presented here together with data on the possible location of phospholipase activity in intact mycobacteria.

\section{Methods}

Mycobacteria from experimentally infected animals. M. avium CR1/69 and $M$. microti OV254 were obtained from heavily infected murine tissue as described previously (Wheeler, 1987). Briefly, bacteria were separated from tissue by a method (World Health Organization, 1980) involving differential then density-gradient centrifugation. For suspensions used to provide cell-free extracts for enzyme work, further purification was achieved on an aqueous two-phase system. Some 
suspensions were treated for $30 \mathrm{~min}$ with $0.5 \mathrm{M}-\mathrm{NaOH}$ at $25^{\circ} \mathrm{C}$ (Wheeler et al., 1982) to abolish host-derived activities adsorbed to the surface of the bacteria. Host-derived organisms were enumerated by direct counting.

Mycobacteria grown in cell-free media. Bacteria were grown in $100 \mathrm{ml}$ Dubos medium (Chadwick, 1982) in $250 \mathrm{ml}$ flasks, shaken at 200 r.p.m. at $37^{\circ} \mathrm{C}$, then harvested, as described previously (Wheeler, 1987) after $15 \mathrm{~d}$ ( $M$. microti OV254) or $16 \mathrm{~d}$ ( $M$. avium CR1/69). The inocula used ( $1 \mathrm{ml}$ per flask) were from similarly grown cultures. Where indicated palmitate $\left(100 \mu \mathrm{g} \mathrm{ml}^{-1}\right)$ or liposomes were added to the Dubos medium. Liposomes containing phosphatidylcholine, cholesterol and $s n-1,2-$ dipalmitoylphosphatidic acid (all from Sigma, details of composition given in Wheeler et al., 1990) in the molar ratio $10: 10: 1$, were prepared as described previously (Kondo et al., 1985; Wheeler et al., 1990) and were equivalent to $150 \mu \mathrm{g}$ lipid $(\mathrm{ml} \text { medium })^{-1}$.

Bacteria were also grown in Sauton's medium (Chadwick, 1982) to which liposomes (exactly as described above) had been added. Mycobacteria were enumerated by determination of their dry weight by taking 10 to $20 \mathrm{ml}$ samples of cell culture.

Diazotization of intact bacteria. Bacteria were diazotized with 7-diazonaphthalene-1,3-disulphonic acid (ANDS) in exactly the same way as described previously (Wheeler et al., 1982).

Preparation of cell-free extracts of mycobacteria. Mycobacteria were ultrasonically disrupted and clarified as described previously (Wheeler et al., 1990) to give extracts in $0.2 \mathrm{M}$-potassium phosphate, $\mathrm{pH} 7$, with $5 \mathrm{~mm}$-dithiothreitol or $5 \mathrm{~mm}-\mathrm{MES} / \mathrm{KOH}, \mathrm{pH} 7$, with $1 \mathrm{mM}-\mathrm{MgCl}_{2}$. Some extracts were dialysed using ultrafiltration cones with a cut-off of $M_{;}, 25000$ as described previously (Wheeler, 1984). There was no marked difference in the specific activities of the enzymes studied in this paper between the extracts prepared in the different ways described above.

Extracts could be stored at $-70^{\circ} \mathrm{C}$, frozen and re-thawed up to three times. and lyophilized, without discernible loss of phospholipase activity.

Culture filtrates. These were simply culture supernates, centrifuged at $20000 \mathrm{~g}$ for $20 \mathrm{~min}$ to sediment liposomes when present, then concentrated and desalted through ultrafiltration cones with a cut-off of $M_{\mathrm{r}} 25000$. Dubos medium culture filtrate could only be concentrated 7- to 10 -fold as it contained bovine serum albumin. Even at its highest concentration in assays, $3 \%(\mathrm{w} / \mathrm{v})$, albumin did not affect phospholipase activity added from extracts of $\boldsymbol{M}$. microti or $\boldsymbol{M}$. avium. Phospholipase activity was also retained ( 85 to $110 \%$ of original activity) when activity was exposed to the concentration procedures employed with culture filtrates.

\section{Enzyme assays}

Assays for phospholipase activity in mycobacteria were optimized previously (Wheeler \& Ratledge, 1991). A single phospholipid, incluidng ${ }^{14} \mathrm{C}$-labelled phospholipid, was included in each assay. Sources of the unlabelled phospholipids are given elsewhere (Wheeler \& Ratledge, 1991). Abbreviations used in the text together with full names are given below. Assays routinely done with each phospholipid substrate, were as follows.

Phosphatidylcholine $(P C)$. When either L-3-PC, 1,2-di[1-14 C]palmitoyl (NEN; $\left.114 \mathrm{Ci} \mathrm{mol}^{-1}\right)\left(1,2-\mathrm{di}^{1}\left[{ }^{14} \mathrm{C}-16: 0\right] \mathrm{PC}\right)$, or L-3-PC, 1-palmitoyl, 2-[1-14 C]palmitoyl (NEN; $\left.57 \mathrm{Ci} \mathrm{mol}^{-1}\right)\left(2-\left[{ }^{14} \mathrm{C}-16: 0\right] \mathrm{PC}\right)$ were added, unlabelled PC was also included to give $23.8 \mathrm{nmol}$ and $0.40 \mu \mathrm{Ci}$ per $\mathrm{ml}$ of the final assay mixture. $(1 \mathrm{Ci}=37 \mathrm{GBq}$.) When L-3-PC, l-stearoyl, 2-[1-14 C]arachidonyl (NEN; $\left.53 \mathrm{Ci} \mathrm{mol}^{-1}\right)\left(2-\left[{ }^{14} \mathrm{C}\right.\right.$ $20: 4] \mathrm{PC}$ ) was added, at $0.80 \mu \mathrm{Ci}$ per $\mathrm{ml}$ of final assay mixture, no unlabelled phospholipid was included, giving a final concentration of phospholipid in the mixture of $15 \cdot 1 \mathrm{nmol} \mathrm{m} l^{-1}$. The lipid material was dried, either as a stock or in individual assay tubes, then suspended in $10 \mathrm{mM}-\mathrm{MES} / \mathrm{KOH}, \mathrm{pH} 7$, at 10 times the concentration required in the final assay mixtures. The suspensions were mixed vigorously for $30 \mathrm{~s}$ at $25^{\circ} \mathrm{C}$ every $30 \mathrm{~min}$ for $2 \mathrm{~h}$, and $30 \mathrm{~min}$ before assays were started $60 \mu \mathrm{l}$ (aqueous solution) $1 \mathrm{~mm}$-2-lyso-phosphatidylcholine was added per $30 \mu \mathrm{l}$ of suspension. Assays were started by adding $210 \mu \mathrm{l}$ of various rnixtures containing cells or cell-free extracts to the suspensions $(90 \mu \mathrm{l})$. The final assay mixtures $(300 \mu \mathrm{l})$ included $10 \mathrm{~mm}-\mathrm{MES} / \mathrm{KOH}, \mathrm{pH} 7$, and $0.05 \%$ Tween 80 . Suspensions of phosphatidylcholine were always clarified when $0.2 \mathrm{~mm}$-lyso-phosphatidylcholine was included suggesting that the suspension was in the form of mixed micelles (Dennis. 1983).

lyso-Phosphatidylcholine (lyso-PC). The assay mixture routinely included a $0.2 \mathrm{~mm}$ aqueous solution of lyso-PC with labelled L-lyso3-PC, $1-\left[{ }^{14} \mathrm{C}\right]$ palmitoyl (Amersham; $\left.56 \mathrm{Ci} \mathrm{mol}^{-1}\right)\left(1-\left[{ }^{14} \mathrm{C}-16: 0\right]-\right.$ lyso-PC) at $0.5 \mu \mathrm{Ci}$ per $\mathrm{ml}$ of the final assay mixture, with $10 \mathrm{~mm}$ $\mathrm{MES} / \mathrm{KOH}, \mathrm{pH} 7$, and $0.05 \%$ Tween 80 .

Phosphatidylethanolamine (PE). These assays included unlabelled PE and L-3-PE. 1,2-di[1-14 Clpalmitoyl (Amersham; $\left.110 \mathrm{Ci} \mathrm{mol}^{-1}\right)(1,2-$ $\left.\operatorname{di}\left[{ }^{1+} \mathrm{C}-16: 0\right] \mathrm{PE}\right)$ to give $23 \cdot 8 \mathrm{nmol}$ and $0.40 \mu \mathrm{Ci}$ per $\mathrm{ml}$ of the final assay mixture. Assays were done as described for phosphatidylcholine, except that 2-lyso-PC was not added and final assay mixtures contained $5 \mathrm{mM}-\mathrm{CaCl}_{2}$.

Assay procedures. All assays were performed at $34^{\circ} \mathrm{C}$. In assays using cell-free extracts, $70 \mu \mathrm{l}$ samples were taken at intervals up to $100 \mathrm{~min}$ except for assays with $1-\left[{ }^{14} \mathrm{C}-16: 0\right]$ lyso-PC when the final sample was taken at $30 \mathrm{~min}$. A minor modification which did not discernibly affect phospholipase activity was to scale down assays to $200 \mu$ when cell-free extract (the source of enzyme) was scarce and take three $60 \mu \mathrm{l}$ samples. A sample was always taken at zero time (in practice within $15 \mathrm{~s}$ of mixing substrates and cell extract).

In assays using intact bacteria, a $60 \mu \mathrm{l}$ sample was taken immediately after mixing, then the assay vial was left open and placed inside a Universal bottle $(25 \mathrm{ml})$ containing $400 \mu \mathrm{l} 0.5 \mathrm{M}-\mathrm{NaOH}$. A further sample of assay mixture $(60 \mu \mathrm{l})$ was usually taken at $1 \mathrm{~h}$, then the remaining assay mixture and the $\mathrm{NaOH}$, containing any ${ }^{14} \mathrm{CO}_{2}$ evolved, were sampled at $4 \mathrm{~h}$. As ${ }^{14} \mathrm{CO}_{2}$ levels were very low $(<20 \%$ of the label released by phospholipase), they are not presented.

Controls were always done in parallel with assays including cell-free extract or intact bacteria. Controls included water in place of the source of enzyme, or heat-killed $\left(100{ }^{\circ} \mathrm{C}, 15 \mathrm{~min}\right)$ bacteria. When it was discovered that similar results were obtained with either control, controls using heat-killed bacteria were performed only rarely.

Measuring and calculating phospholipase activities. A high performance thin layer chromatography (HPTLC)-based method, described previously (Wheeler \& Ratledge, 1991), was used. In calculating activities, control values were subtracted from sample values. Activity was calculated from the percentage label in the fatty acid in each assay sample to eliminate sampling errors which would arise if absolute counts were used (Wheeler \& Ratledge, 1991). With intact bacteria, label increased with time in the triacylglycerol fraction rather than the fatty acid fraction. In this case, the percentage label in the triacylglycerol fraction was used in calculations. However, results are still expressed as fatty acid released since formation of ${ }^{14} \mathrm{C}$-labelled triacylglycerol is presumably the result of a subsequent, esterification reaction. The activity was calculated from the maximum rate of the reaction, usually the initial rate.

Protein in enzyme sources such as extracts was determined by the Lowry method.

Student's $t$-test was used to determine statistical significance, when required. 


\section{Results and Discussion}

\section{Utilization of phosphatidylcholine during mycobacterial growth and its effect on growth}

Phospholipids may be substrates for pathogenic mycobacteria. It was important, therefore, to establish their effect on growth as growth rate might affect enzyme synthesis. The growth of $M$. microti and $M$. avium was similar to previously reported growth on Dubos medium (Wheeler, 1987). Addition of lipids and phospholipids to Dubos medium had no discernible effect on yields of $M$. avium. Although the growth of $M$. microti in Dubos medium with liposomes added (Fig. 1) was similar to growth in Dubos alone (Wheeler, 1987), the yield was consistently $8 \%$ higher $(P<0.05)$. In contrast, palmitate at $100 \mu \mathrm{g} \mathrm{ml}^{-1}$ inhibited the growth yield of $M$. microti by $70 \%$.

Yields of $M$. microti from Sauton's medium (with or without liposomes added) were poor, just $35 \%$ of those shown in Fig. 1. However, yields (after $16 \mathrm{~d}$ ) of M. avium grown in Sauton's medium + liposomes were around $35 \mathrm{mg}$ per $100 \mathrm{ml}$, which is about $75 \%$ of the growth yield in the much richer Dubos medium.

The data in Fig. 1 show that the phosphatidylcholine in liposomes is used by $M$. microti. However, the rate of appearance of label from $1,2-\mathrm{di}\left[{ }^{14} \mathrm{C}-16: 0\right] \mathrm{PC}$ in $M$. microti organisms growing in media with labelled liposomes was slow (Fig. 1). After $22 \mathrm{~d}, 3.5 \%$ of the label, equivalent to about $0.5 \mathrm{mg}$ phospholipid, had been incorporated into $56 \mathrm{mg} \mathrm{M}$. microti organisms, which contain about $20 \mathrm{mg}$ lipid (Draper, 1982). About half the radioactivity in all samples of washed bacteria was wallbound lipid that could not be extracted with chloroform/ methanol $/ 1 \mathrm{M}-\mathrm{HCl}\left(16: 6: 1\right.$, by vol.) at $20^{\circ} \mathrm{C}$ for $20 \mathrm{~h}$. About $70 \%$ of the extractable label could be traced as triacylglycerol. Therefore, in an attempt to enhance phosphatidylcholine utilization, lyso-phosphatidylcholine $(0.2 \mathrm{~mm})$ was added to Dubos + liposomes medium. Previously, enhancement of activity had been observed in assays of 30 to $60 \mathrm{~min}$ duration (Wheeler \& Ratledge, 1991). However, incorporation of label into washed $M$. microti (Fig. 1) and its wall-bound lipids was not enhanced during growth in the presence of lysophosphatidylcholine. Phospholipase activity was, however, enhanced as indicated by the increased rate of $\mathrm{CO}_{2}$ release and relatively rapid appearance of label in fatty acid released into the medium.

Similar results to those obtained with $M$. microti and shown in Fig. 1 were obtained in single growth experiments with $M$. avium (not shown).

Thus, phospholipids are hydrolysed by mycobacteria in these liquid culture media; however, the fatty acyl groups released are only slightly incorporated into the mycobacterial lipids, and slightly degraded to $\mathrm{CO}_{2}$.

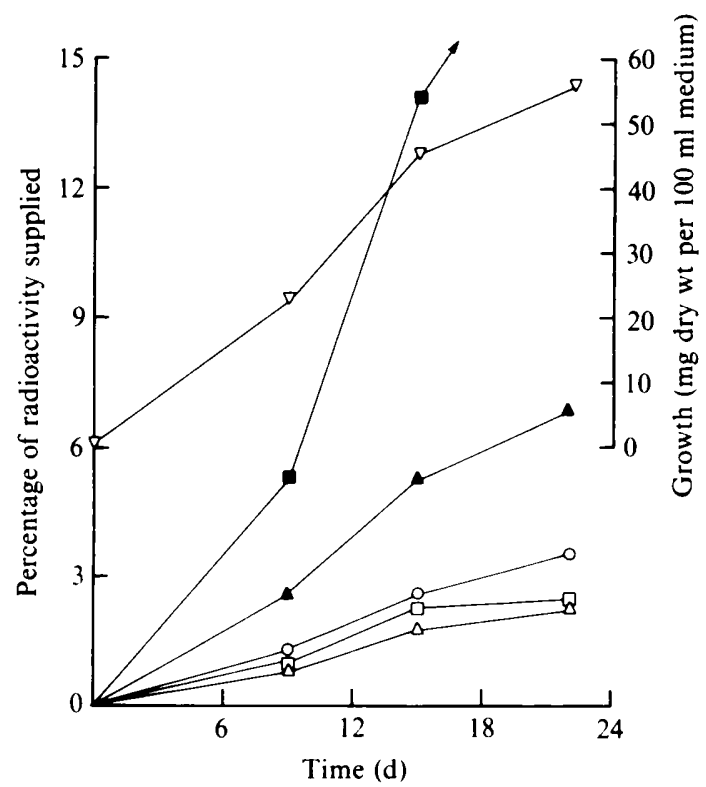

Fig. 1. Utilization of phosphatidylcholine by $M$. microti. $M$. microti was grown in Dubos medium $(100 \mathrm{ml})+$ liposomes including $1 \mu \mathrm{Ci}$ (37 kBq) 1,2-di[ $\left.{ }^{1+} \mathrm{C}-16: 0\right] \mathrm{PC}$, with or without $0 \cdot 2 \mathrm{~mm}-$ lyso-PC. Background levels of radioactivity $(<0.7 \%)$ associated with cells at time zero were subtracted from values obtained during growth. $O$, Radioactivity associated with washed bacteria (not significantly affected by growth in presence of lyso-PC). $\square, \square$, Radioactivity released into the medium as fatty acid with $(\square)$ or without $(\square)$ lyso-PC in the medium. $\triangle, \triangle$, Radioactivity released as $\mathrm{CO}_{2}$ with $(\Delta)$ or without $(\triangle)$ lyso-PC in the medium. $\nabla$, Growth (not significantly affected by lyso-PC in the medium). The values given are representative values from two experiments (individual values were within $10 \%$ of values reported).

\section{Range of phospholipids hydrolysed}

As with M. leprae (Wheeler \& Ratledge, 1991), $M$. microti (Table 1) and $M$. avium (Table 2) have phospholipase activity for releasing fatty acids from all the phospholipids that were tested. It was confirmed that the assay conditions, previously established as optimal for $M$. microti and $M$. leprae, were also optimal for $M$. avium. Thus, substituting unlabelled lyso-PC with $5 \mathrm{mM}-\mathrm{CaCl}_{2}$ enhanced activity towards $1,2-\mathrm{di}\left[{ }^{14} \mathrm{C}-16: 0\right] \mathrm{PE}$, and lowering the assay $\mathrm{pH}$ to 4.4 reduced all phospholipase activities.

\section{Control of phospholipase activity}

All acyl-releasing phospholipase activities in both $\boldsymbol{M}$. microti (Table 1) and $M$. avium (Table 2) were inducible. The activities shown in Tables 1 and 2 were similar whether they were obtained in dialysed extracts or in extracts which had not been dialysed, suggesting that low activity in mycobacteria grown in Dubos medium was not a result of feedback inhibitors remaining in the extracts. 
Table 1. Phospholipase-dependent release of fatty acid from phospholipids by extracts of $M$. microti

Values are mean specific activities [pmol fatty acid released $\left.\min ^{-1}(\mathrm{mg} \text { protein })^{-1}\right] \pm$ SEM with relative activities $\left({ }^{14} \mathrm{C}\right.$-labelled fatty acid released from phosphatidylcholine equals 100$)$ in parentheses. Relative activity values are combined where there is no significant difference $(P<0.05)$ in their values in extracts from mycobacteria grown on different media. Each value was obtained by performing two to four assays with each of at least two extracts prepared from different batches of bacteria.

\begin{tabular}{|c|c|c|c|c|c|c|}
\hline \multirow{2}{*}{$\begin{array}{l}\text { Growth } \\
\text { medium }\end{array}$} & \multicolumn{6}{|c|}{ Fatty acid release from: } \\
\hline & 1,2-di[ $\left[{ }^{4} \mathrm{C}-16: 0\right] \mathrm{PC}$ & $2 \cdot-\left[{ }^{14} \mathrm{C}-16: 0\right] \mathrm{PC}$ & $2-\left[{ }^{1+} \mathrm{C}-20: 4\right] \mathrm{PC}$ & $1,2-\mathrm{di}\left[{ }^{14} \mathrm{C}-16: 0\right] \mathrm{PE}$ & $1-\left[{ }^{4} \mathrm{C}-16: 0\right] / y$ & vso-PC \\
\hline Dubos & $47 \pm 12$ & $11 \pm 4$ & ND & $86 \pm 34(183)$ & $982 \pm 275$ & \\
\hline Dubos + liposomes & $432 \pm 88$ & $61 \pm 15$ & $103 \pm 43(70)$ & $257 \pm 45$ & $7336 \pm 1912$ & $(465)$ \\
\hline Dubos + palmitate & GI & GI & ND & GI & $\mathrm{Gl} \sim 250$ & \\
\hline Mice & $176 \pm 40$ & ND & ND & $190^{*} \quad(108)$ & $3725 \pm 698$ & \\
\hline
\end{tabular}

ND, Not determined.

GI, Growth inhibitory.

- Single determination.

Table 2. Phospholipase-dependent release of fatty acid from phospholipids by extracts of $M$. avium

Values, assays and reproducibility of results are exactly as indicated in Table 1.

\begin{tabular}{lccccc}
\hline \hline \multirow{2}{*}{$\begin{array}{c}\text { Growth } \\
\text { medium }\end{array}$} & \multicolumn{5}{c}{ Fatty acid release from: } \\
\cline { 2 - 6 } & 1,2 -di[ $\left.{ }^{14} \mathrm{C}-16: 0\right] \mathrm{PC}$ & $2-\left[^{14} \mathrm{C}-16: 0\right] \mathrm{PC}$ & $2-\left[^{14} \mathrm{C}-20: 4\right] \mathrm{PC}$ & 1,2 -di[ $\left.{ }^{14} \mathrm{C}-16: 0\right] \mathrm{PE}$ & $1-\left[{ }^{14} \mathrm{C}-16: 0\right] l y s o-\mathrm{PC}$ \\
\hline Dubos & $36 \pm 6$ & $4 \pm 2(22)$ & ND & $56 \pm 15(156)$ & $161 \pm 23(106)$ \\
Dubos + liposomes & $241 \pm 38$ & $67 \pm 4(55)$ & $66 \pm 4(94)$ & $333 \pm 82(138)$ & $2152 \pm 286(211)$ \\
Dubos + palmitate & $464 \pm 152$ & $51 \pm 25(22)$ & $53 \pm 10(40)$ & $327 \pm 89(70)$ & $1989 \pm 169(101)$ \\
Mice & $124 \pm 44$ & $39^{*}(63)$ & ND & $116 \pm 16(94)$ & $821 \pm 255(157)$ \\
\hline \hline
\end{tabular}

ND, Not done.

- Single determination.

Induction of phospholipase was observed in $M$. microti and $M$. avium when liposomes, rich in phospholipids, were added to Dubos medium. Palmitate also induced phospholipase activities in $M$. avium. It may seem surprising for a fatty acid to induce an enzyme which would release further fatty acids (from phospholipids). However, fatty acids are toxic and do not usually occur in a free form. Thus, phospholipase activity may normally be induced by the fatty acids released in initially small amounts from lipids by the low uninduced enzyme activities observed in this study. Alternatively, a wide range of lipids and phospholipids may be recognized as inducers [probably indirectly, as they are unlikely to bind directly to (phospholipase) genes] and fatty acids are amongst these lipids because their effect has never been selected against as they are not normally present at significant concentrations in vivo. Palmitate did not, however, induce activity in $M$. microti, but this may be due to the severe inhibition of growth caused.
Phospholipase activities were higher in mycobacteria grown in mice than in the lipid-free Dubos medium. Activities were not as high as when growth was in axenic medium with liposomes, but this again may reflect differences in growth. Growth in mice was slightly slower than in Dubos medium with or without liposomes (Wheeler et al., 1990). Direct comparisons can now be made with phospholipase activity in $M$. leprae (Wheeler \& Ratledge, 1991) and other in vivo-grown mycobacteria. Thus specific activity in extracts of $M$. leprae/specific activity in extracts of $M$. microti or M. avium $\times 100$ is 66 to 93 for $1,2-\operatorname{di}\left[{ }^{14} \mathrm{C}-16: 0\right] \mathrm{PC}, 44$ to 197 for $1-\left[{ }^{14} \mathrm{C}\right.$ $16: 0]$ lyso-PC and 68 to 112 for $1,2-\mathrm{di}\left[{ }^{14} \mathrm{C}-16: 0\right] \mathrm{PE}$.

Phospholipase activities for different substrates did not all appear to be co-induced. This is illustrated, for example, by the low relative activities for release of fatty acid (i.e. palmitate) from $2-\left[{ }^{14} \mathrm{C}-16: 0\right] \mathrm{PC}$ in $M$. avium grown in Dubos or Dubos + palmitate compared with this activity in $M$. avium grown in Dubos + liposomes or 


\section{Table 3. Effect of diazotization on phospholipase activity}

Values are means of the specific activity in cell-free extract from diazotized bacteria/specific activity in cell-free extract from untreated bacteria $\times 100$ for bacteria from a single growth batch. Cell extracts were prepared from each of two batches of both $M$. microti and $M$. avium grown in Dubos medium + liposomes. Two to four determinations of the phospholipase activities indicated were made with each extract, except where stated below. SEM values were calculated from the variance in activities in extracts from diazotized bacteria. Specific activity values (mean \pm SEM) in extracts from untreated bacteria are presented in Tables 1 and 2 .

\begin{tabular}{|c|c|c|}
\hline \multirow[b]{2}{*}{ Substrate } & \multicolumn{2}{|c|}{$\begin{array}{l}\text { Phospholipase activity in extracts } \\
\text { from diazotized bacteria relative to } \\
\text { activity in untreated controls } \\
\text { (means } \pm \text { SEM) }\end{array}$} \\
\hline & M. microti & M. avium \\
\hline $\begin{array}{l}1,2-\mathrm{di}\left[{ }^{14} \mathrm{C}-16: 0\right] \mathrm{PC} \\
2-\left({ }^{14} \mathrm{C}-20: 4\right] \mathrm{PC} \\
1-\left[{ }^{14} \mathrm{C}-16: 0\right] \text { lyso-PC } \\
1,2-\mathrm{di}\left[{ }^{14} \mathrm{C}-16: 0\right] \mathrm{PE}\end{array}$ & $\begin{array}{l}15 \pm 10 \\
25 \pm 4 \\
57 \pm 22 \\
\quad \mathrm{ND}\end{array}$ & $\begin{aligned} 78 & \pm 15 \\
100 & \pm 10^{*} \\
103 & \pm 20 \\
59 & \pm 5^{*}\end{aligned}$ \\
\hline
\end{tabular}

ND, Not done.

* Determinations on a single batch only.

in mice (Table 2). This may indicate that there are two enzymes involved in release of fatty acid from 1,2-di[ $\left.{ }^{14} \mathrm{C}-16: 0\right] \mathrm{PC}$ and $2-\left[{ }^{14} \mathrm{C}-16: 0\right] \mathrm{PC}$.

There are further, also indirect, lines of evidence which may suggest that there is more than one enzyme with phospholipase activity in each pathogenic mycobacterium. As in M. leprae (Wheeler \& Ratledge, 1991), optimal fatty-acid-releasing phospholipase activity - in both $M$. microti and $M$. avium - required different physical forms (see Methods for details) of the substrates for each of PE, PC and lyso-PC (Dennis, 1983). Further, diazotization experiments suggested that in $M$. avium, activity with PE was more exposed to the surface than other activities, while in $M$. microti phospholipase activity was more exposed than lysophospholipase (i.e. against $l y s o-P C$ ) activity (Table 3 ). Thus, there may be an array of phospholipases allowing pathogenic mycobacteria fine control over their phospholipid metabolism, and the ability to respond to the availability of different types of phospholipid separately.

The types of activity shown, in both $M$. microti and $M$. avium, were similar to those in $M$. leprae, and were $\mathrm{A}_{1}$ (EC 3.1.1.3; phosphatidylcholine 1-acyl-hydrolase), $\mathrm{A}_{2}$ (EC 3.1.1.4; phosphatidylcholine 2-acyl-hydrolase) and lysophospholipase (EC 3.1.1.5; lysophosphatidylcholine acyl-hydrolase). Evidence for $\mathrm{A}_{2}$ activity comes from the release of ${ }^{14} \mathrm{C}$-labelled fatty acid from $2-\left[{ }^{14} \mathrm{C}\right.$ fatty acyl]PC. $A_{1}$ activity must also be present since specific activities were higher with $1,2-\left[{ }^{14} \mathrm{C}\right.$-fatty acyl]PC than $2-\left[{ }^{14} \mathrm{C}\right.$-fatty acyl]PC. If the 2 -acyl group only was being released (by $A_{2}$, with no $A_{1}$ activity) then the specific activities with the two labelled substrates above would be equal. Lysophospholipase activity is responsible for the enzymic hydrolysis of $1-\left[{ }^{14} \mathrm{C}\right] l y s o-\mathrm{PC}$.

\section{Location of phospholipase activity}

Phospholipase (fatty-acid-releasing) activity was associated with bacteria. It is not secreted. Only traces of activity - with either $1,2-\mathrm{di}\left[{ }^{14} \mathrm{C}-16: 0\right] \mathrm{PC}$ or $1-\left[{ }^{14} \mathrm{C}\right.$ 16:0]lyso-PC - appeared in culture filtrates. Selecting culture media for these experiments with $M$. microti presented a problem as the culture filtrate of Dubos medium (with added liposomes) was difficult to concentrate as it contained albumin, and growth was poor on Sauton's medium. Even so, in the worst case, the limit of detection of activity in the culture filtrate was $3 \%$ of the total activity (in micro-organisms plus culture filtrate), and when activity could be detected in the culture filtrate, only up to $1.5 \%$ of the total could be detected. With $M$. avium, which grew well on Sauton's medium + liposomes, culture filtrate could be concentrated to about $2 \%$ of the original volume to allow easier detection of any secreted enzyme. The maximum activity to appear in culture filtrate was lysophospholipase, at only $0.2 \%$ of the total activity. With both $M$. microti and $M$. avium, culture filtrates were assayed after the logarithmic phase of growth $(8,15$ and $22 \mathrm{~d})$ thus maximizing any appearance of phospholipase in the medium.

Diazotization of the cells to abolish surface enzyme activities revealed a diversity in location of phospholipase activity. Previously, we showed that the diazotizing agent ANDS did not in general react with phospholipase activities of intact $M$. leprae (Wheeler $\&$ Ratledge, 1991). We argued that this meant that activity was not accessible at the cell surface, assuming that ANDS did not cause any immediate changes in envelope morphology. A similar general conclusion can now be drawn for phospholipase activity of $\dot{\text { in }}$. avium (Table 3 ). Phospholipase activity against phosphatidylethanolamine was only weakly but significantly $(P<0.05)$ inhibited by ANDS treatment. The possibility that the result with phosphatidylethanolamine may have been obtained because $\mathrm{Ca}^{2+}$ was present in the assay was ruled out, as when $\mathrm{Ca}^{2+}$ was used in place of lyso-PC in assays with 1,2-di $\left[{ }^{4} \mathrm{C}-16: 0\right] \mathrm{PC}$, similar results were obtained to those shown in Table 3.

In $M$. microti, however, phospholipase activities were inhibited strongly by ANDS treatment, suggesting a surface location for them (Table 3). Lysophospholipase activity was weakly, but significantly $(P<0.05)$ inhibited, perhaps indicating some crypticity.

With the apparent surface location for phospholipase activity in $M$. microti, it might be expected that this organism would hydrolyse exogenous phospholipids. 
However, intact $M$. microti were no better at hydrolysing 1,2-di[ $\left.{ }^{14} \mathrm{C}-16: 0\right] \mathrm{PC}$ and $1-\left[{ }^{14} \mathrm{C}\right] l y s o-\mathrm{PC}$ than intact $M$. avium; in both strains activities detectable in intact bacteria were between 5 and $12 \%$ of the activities in their extracts. Notably, intact $M$. avium hydrolysed phospholipids even though its phospholipase activity was not accessible to ANDS at its surface. The latter observation can be rationalized as follows: bacteria are permeable to phospholipids (Daum \& Paltauf, 1990) so the phospholipids could reach the site of phospholipase(s) in $M$. avium, while ANDS, which does not penetrate lipid barriers such as the mycobacterial envelope, could not. The failure of intact $M$. microti to hydrolyse phospholipases more rapidly than $M$. avium may be due to modulation of phospholipase activity by envelope components, perhaps glycolipids. In $M$. leprae, phospholipase activity may similarly be inhibited by the phenolic cell envelope glycolipid (Wheeler \& Ratledge, 1991).

\section{Role of acyl-hydrolysing phospholipases in pathogenic mycobacteria}

Phospholipase activity for releasing fatty acids from phospholipids is clearly induced in pathogenic mycobacteria by exogenous phospholipids. In nature, these microbes are only likely to encounter phospholipids when they are inside a host. The observation of relatively high phospholipase activity in mycobacteria harvested from host tissue is consistent with the view that the role of their phospholipases is to release fatty acyl moieties from host phospholipids.

Phospholipase activity is not secreted or readily detectable in intact mycobacteria - even in $M$. microti where diazotization experiments suggest a surface location. As we suggested previously (Wheeler \& Ratledge, 1991), this indicates a non-aggressive role for phospholipases in the mycobacteria studied. The main role may be nutritional, supplying the fatty acids required (Wheeler et al., 1990) by these mycobacteria when they are growing in host cells.

Host-membrane-mycobacterium interactions may be modelled using mixtures of mycobacteria and liposomes which are in close contact (Kondo et al., 1985). Liposomes are disrupted, with phospholipase-dependent fatty acid release occurring as a distinct activity from, and slower than, general disruption (Kondo et al., 1985).
Thus, a picture is emerging of a complex interaction of mycobacterial and host lipids and mycobacterial phospholipases. Such interaction perhaps allows controlled release of fatty acids enabling intracellular mycobacteria to gain nutrition from their hosts without causing major damage, as perforce these agents of chronic disease must.

P.R.W. is grateful to the MRC and the UNDP (World Bank) WHO Special Programme for Research and Training in Tropical Diseases for financial support during the course of this investigation. WHO (IMMLEP programme) provided funds for the maintenance of armadillo colonies. We thank Angela Hare, then subsequently Paula Fields for their excellent technical assistance during this project.

\section{References}

CHADWICK, M. V. (1982). Mycobacteria. Institute for Medical Laboratory Sciences Monographs. Bristol: P. S. G. Wright.

Daum, G. \& Paltauf, F. (1990). Lipid transport in microorganisms. Experientia 46, 586-592.

DennIs, E. A. (1983). Phospholipases. In Lipid Enzymology: The Enzymes, vol. 16, pp. 307-353. Edited by P. D. Boyer. New York: Academic Press.

DRAPER, P. (1982). The anatomy of mycobacteria. In The Biology of the Mycobacteria, vol. 1, pp. 9-52. Edited by C. Ratledge \& J. Stanford. London: Academic Press.

FINNERTY, W. R. (1989). Microbial lipid metabolism. In Microbial Lipids, vol. 2, pp. 525-566. Edited by C. Ratledge \& S. G. Wilkinson. London: Academic Press.

Kashiwabara, Y., Nakagawa, H. \& Matsuki, G. (1980). Phospholipid deacylating activities in murine leprosy bacilli. Journal of Biochemistry 88, 1861-1868.

Kondo, E., SuzukI, K., KanaI, K. \& Yasuda, T. (1985). Liposomesmycobacteria incubation systems as a partial model of host-parasite interaction at cell membrane level. Japanese Journal of Medical Science and Biology 38, 169-180.

WhEELER, P. R. (1984). Oxidation of carbon sources through the tricarboxylic acid cycle in Mycobacterium leprae grown in armadillo liver. Journal of Microbiology' 130, 381-389.

WheELER, P. R. (1987). Biosynthesis and scavenging of purines by pathogenic mycobacteria including Mycobacterium leprae. Journal of General Microbiology 133, 2999-3011.

Wheeler, P. R. \& Ratledge, C. (1991). Phospholipase activity of Mycobacterium leprae harvested from experimentally infected armadillo tissue. Infection and Immunity 59, 2781-2789.

Wheeler, P. R., BharadWaJ, V. P. \& Gregory, D. (1982). $N$-Acetyl$\beta$-glucosaminidase, $\beta$-glucuronidase and acid phosphatase in $M$ ycobacterium leprae. Journal of General Microbiology 128, 1063-1071.

Wheeler, P. R., Bulmer, K. \& Ratledge, C. (1990). Enzymes for biosynthesis de novo and elongation of fatty acids in mycobacteria : is Mycobacterium leprae competent in fatty acid biosynthesis? Journal of General Microbiology 136, 211-217.

World Health Organization (1980). UNDP/World Bank/WHO Special Programme for Research and Training in Tropical Diseases. Report of the Fifth Meeting on the Immunology of Leprosy (IMMLEP). TDR/IMMLEP-SWG (5)/80.3, Annex 4, p. 23. Geneva: World Health Organization 